\title{
Which locations offer the best potential returns for UK retail investors?
}

Received (in revised form): 13 October 2005

\section{David Erwin}

is a partner of Cushman \& Wakefield where he began his career in 1986. He now heads the Retail Investment team of the Capital Markets Group. He works with institutional and investment clients in the acquisition and sale of all sectors of the retail investment market and has advised a number of leading tenants in major sale and leaseback programmes since the $1990 \mathrm{~s}$. He contributes regularly to the property press and has spoken at Henry Stewart Conferences.

\section{Emma Harding}

is a research analyst for property consultant Cushman \& Wakefield, where she has worked for the firm's European Research Group specialising in investment strategy and forecasting for the last two years. Prior to this she worked as a researcher for an independent fund management company.

\section{Indeesh Bhogal}

has worked in property research for five years, joining Cushman \& Wakefield in 2000 and is now specialising in indirect investment for the firm's Capital Markets Group. Before this she worked in the Economics Group at Schroder Investment Management.

\section{Abstract}

This paper discusses the Cushman \& Wakefield TopTowns model and summarises how, using a variety of inputs, the model attempts to gauge the real estate investment potential of 300 top retail locations in the UK. The model has been developed following a period of strong outperformance by property returns relative to other asset classes - and competition for the investment medium is increasingly evident, requiring a higher level of sophistication in the investment decision-making process to identify long-term targets.

The firm identified a need to determine how to predict investment potential at a local level within the UK, in order to deliver the best returns for clients. Drawing on in-house Researchers, retail leasing agents and investment agents, the firm was able to produce a model that would help in the investment decisionmaking process to identify long-term targets at a town level. The model is only one of the tools that should be used in stock selection, but it provides a rigorous corporate framework to improve the effectiveness of tactical and strategic selection.

David Erwin

Cushman \& Wakefield 43-45 Portman Square London W1A $3 \mathrm{BG}$, UK Tel: +44 (o) 2071525016 Fax: + 44 (0) 2071525381 E-mail: david.erwin@eur. cushwake.com

\section{Keywords:}

retail investment analysis, town ranking model, past and future performance

Journal of Retail and Leisure Property (2006) 5, 104-116.

doi:10.1057/palgrave.rlp.5100004 


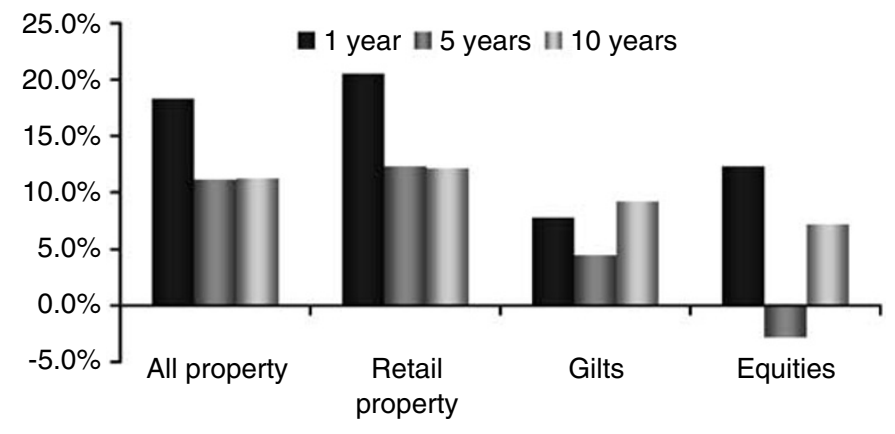

Figure I: Total returns across asset classes on a per annum compound basis to December 2004 Source: IPD, Cushman \& Wakefield

\section{MODELLING INVESTMENT POTENTIAL}

The property market has outperformed other asset classes over the last three, five and ten years, and as such is attracting interest from investors both inside and outside the UK, to some degree irrespective of the economic environment.

Whilst performance patterns have shifted somewhat in the last twelve months, 2004 in particular was an extremely good year for property, and saw total returns reaching an 11-year high of 18.3 per cent, compared to 6.6 per cent and 12.8 per cent for Gilts and equities respectively (Figure 1). Within the property sector, retail was the star-performer with a total return of approximately 20.5 per cent. The average return for retail over the past five or ten years, whilst somewhat less vigorous, has outperformed both property as a whole as well as other investment markets, a factor which has continued to attract investors into the market.

While it is clear that property holds appeal to both new and existing investors, there is little analysis that will help to pinpoint opportunities at, for example, town level, with most analysis focusing on returns either by sector or by region.

Against this backdrop, Cushman \& Wakefield has developed a model designed to look at retail property on a town-by-town basis, in order to gauge those locations that will support the highest rents in the mediumterm, say a ten-year horizon. The aim of the model is to consider the long-term structural potential of each market on a relative and riskadjusted basis. Interpreting this in terms of current areas of opportunity will require a more detailed analysis of supply and current market pricing.

\section{STATISTICAL ANALYSIS}

Based on its experience of analysing retail investments and retailer requirements, the firm identified a number of variables which appeared to be responsible for determining future performance. These variables included the local economy, socio-demographic data, the local environment and property data (Figure 2).

A fundamental part of the process was the identification of those factors which impact on the local retail property market and thus act either to support or to diminish returns in the long run. Common sense suggests that certain variables, such as those specific to the macro 
Figure 2: Integrated variables

\begin{tabular}{llll}
\hline Economic & Socio-demographic & Property & Environment \\
\hline $\begin{array}{l}\text { Current unemployment } \\
\text { Historic unemployment }\end{array}$ & $\begin{array}{l}\text { Catchment population } \\
\text { Catchment population } \\
\text { growth }\end{array}$ & $\begin{array}{l}\text { Rental growth volatility } \\
\text { Recent rental growth }\end{array}$ & $\begin{array}{l}\text { In-town accessibility } \\
\text { Out-of-town accessibility }\end{array}$ \\
$\begin{array}{llll}\text { Expenditure per person } \\
\text { Persons per multiple } \\
\text { retailer }\end{array}$ & Current supply & Location rating \\
$\begin{array}{l}\text { Current employment } \\
\begin{array}{l}\text { Regional employment } \\
\text { forecast }\end{array}\end{array}$ & $\begin{array}{l}\text { Potential supply } \\
\text { Quality of stock }\end{array}$ & Improving/static/declining \\
$\begin{array}{l}\text { Regional economic } \\
\text { growth forecast }\end{array}$ & Investor demand & \\
& & Retailer demand & \\
& & Yield pricing & \\
\hline
\end{tabular}

economy or that are property related, eg historical rental growth, will have an impact on the market.

A wide range of variables from the four different categories were examined and their correlations with the locations' rental levels were revealed. A mix of both quantitative and qualitative data was used in order to combine both statistical data and specialised market knowledge to create meaningful, decision-enhancing results. As a result, a total of 21 variables were deemed to be most correlated with the retail market, as shown in Figure 2. Figure 3 shows the factors that were identified as having the highest correlations and therefore the greatest impact on potential performance. If the $t$-statistic is higher than 2 , the variable is statistically proven to have an impact on the rental level.

Overall, the factors identified were considered to give a good range of both qualitative and quantitative variables spanning a variety of areas, which would then provide a realistic model that would be reflective of the retail-investment market.

\section{KEY CRITERIA - IN MORE DEPTH...}

Whilst the majority of the factors that have been utilised within the model are self-explanatory, some of the key property criteria may require further clarification. These variables also tend to show a higher correlation with the rental level, suggesting that they are of relatively higher importance to the overall model.

- Current supply: Rates the current supply of prime retail units in the central area of the given location. This factor is designed to determine whether the town is over- or under-supplied at the present time.

- Potential supply: Looks at the potential for further supply of prime units in the central area of the location. It is also important to examine whether the location is able to support an increased supply of retail units in the medium term.

- Improving/static/declining: This factor examines the perception of the town within the UK's retailing hierarchy. Local initiatives, for example increased funding from the government or regeneration of 
Figure 3: Rental level correlations: Top five

\begin{tabular}{lll}
\hline Variable & Correlation (\%) & t-statistic \\
\hline Location rating & 81 & 23.29 \\
Quality of stock & 79 & 22.00 \\
Investor demand & 74 & 18.67 \\
Yield pricing & 68 & 17.22 \\
Persons per multiple retailer & 61 & 16.01 \\
\hline
\end{tabular}

certain areas, that are designed to improve the perceptions of the location are also taken into account within the rating.

- Yield pricing: Examines the current yield level and looks at whether yields in the location are either at their correct level or are mispriced given current conditions. The factor takes into account whether there is scope for further hardening or softening of the yield level in the short term.

- Investor demand: Looks at the current level of interest within the location from investors.

- Retailer demand: Examines the current level of interest within the location for prime units/space from retailers.

\section{THE CREATION OF THE MODEL}

Once the relevant factors had been discovered, the modelling process could begin. The first step was to weight each factor in terms of the expected impact on the investment potential of a location. The weighting reflects an amalgamation of the correlations that resulted from the testing process and general theory according to market knowledge. Once finalised, the weighting bands were as set out in Figure 4.

The majority of the variables, as would be expected, have been included in the middle category and cover each of the four areas shown. Several of these, however, are economy-specific variables, reflecting the significant impact that economic drivers have on the rental level in general. Perhaps surprisingly, both unemployment variables were discovered to be rather less significant than the other factors, therefore justifying only low weightings in the overall model. This, however, is true

Figure 4: Model weightings

\begin{tabular}{lll}
\hline Low & Medium & High \\
\hline Current unemployment & Regional economic growth forecast & Catchment population \\
Historic unemployment & Catchment population growth & Persons per multiple retailer \\
& Current employment & Yield pricing \\
& Regional employment forecast & Location rating \\
& Expenditure per person & Quality of stock \\
& In-town accessibility score & Investor demand \\
& In-Town accessibility score & Retailer demand \\
& Rental growth volatility & \\
& Recent rental growth & \\
& Improving/static/declining & \\
& Current supply & \\
& Potential supply & \\
\hline
\end{tabular}


of rental forecasting models in general, with employment levels, rather than unemployment itself, acting to drive rental growth across the sectors.

Once the variables had been weighted, the foundation of the model had to be laid. The underlying basis of the model, was, however, relatively straightforward.

In order to bring some form of consistency to the data, a standardisation technique was used. This involved turning the data into a value akin to a z-score (which normalises data by measuring its distance from the mean in standard deviations) and then into a percentage. These figures were then weighted as shown and subsequently aggregated in order to produce a final score for each of the locations from which the final ranking was created.

\section{MODEL OUTPUT}

The modelling process was applied to a total of 300 retail locations in the UK, comprising of 287 towns and a further 13 prominent malls. It was therefore considered prudent to maintain two lists, with one that would focus on towns and another on the malls. As well as highlighting the overall rankings, the output also focuses on where each location falls in terms of each factor area, showing, for example, the location's percentage of the best attainable score for economics.

The second part of the output focuses on the individual locations themselves in significantly more depth. Initially, the location is examined on a factor-by-factor basis in order to enable an investor to decide whether or not the site meets the required parameters. The location itself is also placed into both a regional and national context, showing how each factor performs relative to these areas, before picking out the location's best and worst features.

The final part of the analysis allows for a comparison with the location's local competition and then examines historical rental growth and yield movements at a local, regional and national level. Figure 5a and b shows an example of the output page for Lincoln, ranked 82nd in the analysis.

\section{UPTOWN TOP RANKING...}

The obvious question, of course, is what did the final analysis suggest where are the best places to invest over the next ten years based on the current climate? Figure 6 shows the top thirty towns in terms of retailinvestment potential in Great Britain, according to the TopTowns model.

Most of the top 30, and the top 15 in particular, are not really surprising choices, with large and historically important retailer towns remaining high in the list, suggesting continued long-term potential. Oxford Street, as one of the major shopping streets in London, also makes an anticipated appearance, although its position at only number seven in the list underlines the need for investment in the local area.

Reading, ranked first out of all 300 locations, scored exceptionally highly in the majority of categories: it is expected to see healthy economic growth combined with a flourishing labour market, while being 


\section{TopTowns Model: Oct-2005}

\section{Lincoln 58th}

The following is an assessment of the relative strength and standing of the above as a retail investment centre in the UK in the long-term. The information is derived from Cushiman \& Wakefield Healey \& Baker's TopTowns potential.

The analysis below is based on 2004 data. It shows the data used for each variable and the percentage score awarded, along with the relationships to regional and national average figures for the centres in the database. The scoring rellects the relative spread of values recorded for the 300 centres analysed in the database, placing each centre in context with the sample for each data item. The data is derived from a wide range of sources and is supplied on a confidential basis. Data is sourced from Cushman \& Wakefield Hesley \& Baker, CACL, Experian Business Strategies, GOAD and the ONS.

Further information can be obtained from the European Research Group of Cushman \& Wakefield Healey \& Baker.

\begin{tabular}{|c|c|c|c|c|c|c|}
\hline \multicolumn{7}{|l|}{ Long Term Assessment } \\
\hline \multicolumn{7}{|l|}{ Short/Medium Term Assessment } \\
\hline $\begin{array}{l}\text { The current assessment of Lincoln is } \\
\text { to be very good. }\end{array}$ & Retail prospe & & & & & \\
\hline \multirow[t]{2}{*}{ Assessment Factors } & \multirow[b]{2}{*}{ Factor Weightings } & \multicolumn{2}{|c|}{ Lincoln } & \multicolumn{2}{|c|}{ East Midlands } & \multirow{2}{*}{$\begin{array}{c}\text { Great Britain } \\
\text { Average Data } \\
\text { Input }\end{array}$} \\
\hline & & Data Input & Score & $\begin{array}{l}\text { Average Data } \\
\text { Input }\end{array}$ & Average Score & \\
\hline Regional Economic Growth Forecast & Medium & $1.62 \%$ & $37.1 \%$ & $2.22 \%$ & $46 \%$ & $2.47 \%$ \\
\hline Catchment Population Size & High & 118,678 & $49.5 \%$ & 126,952 & $46 \%$ & 133,889 \\
\hline Catchment Growth (5 year) & Medium & $8.76 \%$ & $63.7 \%$ & $6.07 \%$ & $55 \%$ & $4.58 \%$ \\
\hline Current Unemployment & Low & $1.90 \%$ & $58.1 \%$ & $1.91 \%$ & $31 \%$ & $2.29 \%$ \\
\hline Number Employed & Medium & 148,381 & $38.3 \%$ & 199,399 & $100 \%$ & 419,532 \\
\hline Regional Employment Forecast & Medium & $0.05 \%$ & $43.2 \%$ & $0.35 \%$ & $60 \%$ & $0.50 \%$ \\
\hline Historic Unemployment & Low & $2.00 \%$ & $57.4 \%$ & $2.01 \%$ & $36 \%$ & $2.42 \%$ \\
\hline Comparison Gds per Person & Medium & $5,591.7$ & $39.5 \%$ & $5,589.4$ & $83 \%$ & $6,128.9$ \\
\hline Persons per Multiple Retailer (Goad) & High & 479 & $48.3 \%$ & 623 & $45 \%$ & 669 \\
\hline In-Town Accessibility Score & Medium & 5 out of 10 & $26.8 \%$ & 7 out of 10 & $40 \%$ & 7 out of 10 \\
\hline Out of Town Accessibility Score & Medium & 5 out of 10 & $33.7 \%$ & 7 out of 10 & $34 \%$ & 6 out of 10 \\
\hline Rental Growth Volatility & Medium & $7.79 \%$ & $49.1 \%$ & $6.02 \%$ & $46 \%$ & $7.11 \%$ \\
\hline Recent Rental Growth & Medium & $4.62 \%$ & $45.3 \%$ & $2.93 \%$ & $27 \%$ & $3.74 \%$ \\
\hline Yield Pricing & High & 7 out of 10 & $78.3 \%$ & 6 out of 10 & $51 \%$ & 6 out of 10 \\
\hline Location Rating & High & 7 out of 10 & $70.2 \%$ & 5 out of 10 & $45 \%$ & 5 out of 10 \\
\hline Quality of Stock & High & 6 out of 10 & $59.2 \%$ & 5 out of 10 & $45 \%$ & 5 out of 10 \\
\hline Investor Demand Rating & High & 8 out of 10 & $77.8 \%$ & 5 out of 10 & $44 \%$ & 5 out of 10 \\
\hline Improving/Static/Declining & Medium & 4 out of 5 & $61.1 \%$ & 3 out of 5 & $52 \%$ & 3 out of 5 \\
\hline Current Supply & Medium & 1 out of 5 & $81.0 \%$ & 2 out of 5 & $54 \%$ & 3 out of 5 \\
\hline Retailer Demand Rating & High & 9 out of 10 & $85.1 \%$ & 6 out of 10 & $50 \%$ & 6 out of 10 \\
\hline Potential Supply & Medium & 5 out of 5 & $0.0 \%$ & 3 out of 5 & $41 \%$ & 3 out of 5 \\
\hline Comparative Ranking & & 58th & $55.8 \%$ & 175th & $48 \%$ & 150 \\
\hline
\end{tabular}

Retailer Demand • Current Retail Supply • Catchment Growth Prospects • Yield Pricing • Investor Demand

Above Average Features

Structural Change to Centre $\bullet$ Location Rating • Recent Rental Growth $\bullet$ Catchment Population Size $\bullet$ Quality of Stock • Historic Unemployment $\bullet$ Current Unemployment

Average Features

Below Average Features

Persons per Multiple Retailer $\bullet$ Rental Growth Volatility $\bullet$ Local Labourforce $•$ Expenditure per Capita

Poor Features

Regional Employment Growth • Out of Town Accessibility • Regional Economic Growth • In-Town Accessibility • Potential Retail Supply

\begin{tabular}{|c|c|c|c|c|c|c|}
\hline Competing Centres & Current Rent & Current Yield & Ranking & Distance & $\begin{array}{l}\text { Attraction } \\
\text { /Multiples }\end{array}$ & $\begin{array}{l}\text { Shoppers per } \\
\text { Multiple }\end{array}$ \\
\hline Lincoln & $£ 165.00$ & $4.75 \%$ & 58th & $n / a$ & $401 / 268$ & 479 \\
\hline Nottingham & $£ 250.00$ & $4.50 \%$ & 12th & 38 miles & $1,026 / 585$ & 1,210 \\
\hline Sheffield & $£ 200.00$ & $5.25 \%$ & 80th & 47 miles & $609 / 431$ & 1,618 \\
\hline Peterborough & $£ 210.00$ & $5.00 \%$ & 57 th & 51 miles & $501 / 263$ & 721 \\
\hline Doncaster & $£ 130.00$ & $5.25 \%$ & 145th & 42 miles & $457 / 255$ & 601 \\
\hline Scunthorpe & $E 70.00$ & $5.50 \%$ & 281st & 30 miles & $253 / 157$ & 426 \\
\hline Grantham & {$[60.00$} & $5.75 \%$ & 239th & 33 miles & $200 / 128$ & 447 \\
\hline Grimsby & $£ 120.00$ & $5.50 \%$ & 232nd & 39 miles & $397 / 267$ & 872 \\
\hline Newark & $\ldots$ & $\cdots$ & $n / a$ & 19 miles & $\cdots$ & $\cdots$ \\
\hline Meadowhall & $£ 420.00$ & $5.00 \%$ & 5th & 43 miles & $612 / 258$ & 2,286 \\
\hline$\cdots$ & $\ldots$ & $\cdots$ & $\cdots$ & ... & $\ldots$ & ... \\
\hline
\end{tabular}

Figure 5a: Top Towns model summary page: Please note that the analysis was undertaken prior to the rebranding of C\&W/H\&B to Cashman \&Wakefield 

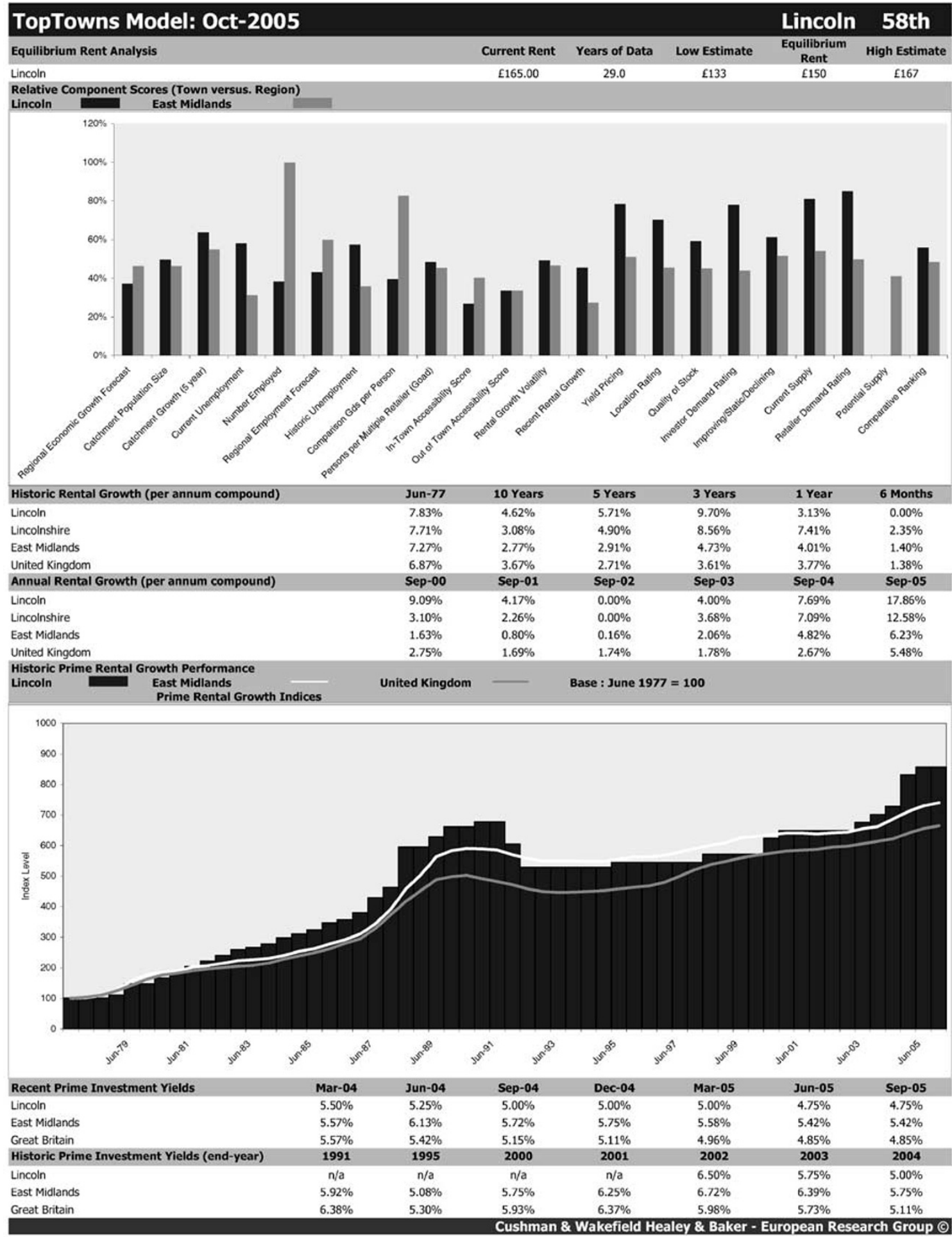

Figure 5b: (continued) 
Figure 6: Top 30 locations - Towns-only ranking

\begin{tabular}{|c|c|c|}
\hline Rank & Location & Region \\
\hline 1 & Reading & South East South \\
\hline 2 & Kingston upon Thames & Suburban London \\
\hline 3 & Guildford & South East South \\
\hline 4 & Cardiff & Wales \\
\hline 5 & Brighton & South East South \\
\hline 6 & Cambridge & East Anglia \\
\hline 7 & Oxford Street W1 & London West End \\
\hline 8 & Glasgow & Scotland \\
\hline 9 & Manchester & North West \\
\hline 10 & Birmingham & West Midlands \\
\hline 11 & Newcastle upon Tyne & North \\
\hline 12 & Nottingham & East Midlands \\
\hline 13 & Leeds & Yorkshire \& Humberside \\
\hline 14 & Leicester & East Midlands \\
\hline 15 & Covent Garden WC2 & London West End \\
\hline 16 & Norwich & East Anglia \\
\hline 17 & Cheltenham & South West \\
\hline 18 & Brompton Road SW3 & London West End \\
\hline 19 & Belfast & Northern Ireland \\
\hline 20 & Milton Keynes & South East North \\
\hline 21 & Chelmsford & South East North \\
\hline 22 & Bath & South West \\
\hline 23 & Oxford & South East North \\
\hline 24 & Bristol & South West \\
\hline 25 & Newbury & South East South \\
\hline 26 & Richmond & Suburban London \\
\hline 27 & Southampton & South East South \\
\hline 28 & Kings Road SW3 & London West End \\
\hline 29 & Chester & North West \\
\hline 30 & Bournemouth & South West \\
\hline
\end{tabular}

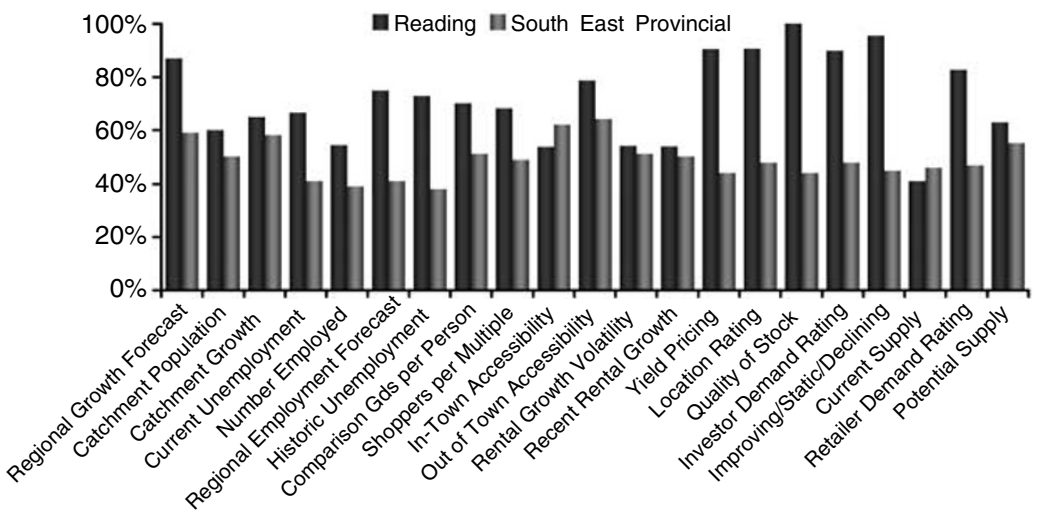

Figure 7: Individual factor scores for Reading in a regional setting (Great Britain $=50$ per cent)

able to attract a large catchment population as a result of its now highly developed retail property market, as shown in Figure 7.

Graphically, it is easy to see why Reading has achieved the top ranking. The town has scored extremely well in the investment-based factors that were weighted most highly, such as the location rating, yield pricing and the general perception of the town ('improving/static/ declining'), while also scoring above the Great British average in all but one of the other areas. One of the major factors that will boost potential in the medium term is that there is in fact little perception of oversupply. 
This will therefore act to encourage both investors and occupiers into the market.

When the current and expected perceptions of the town's retail market across all factor areas are taken in account, therefore, this combines to suggest that there is still significant medium- and long-term potential for both occupiers and investors within the Reading market.

\section{REGIONAL DISPARITIES}

When the list is examined at a regional level, it is clear to see that, again, as would be anticipated, the most favoured region will continue to be the South East/London area (Figure 8). This is logical given the region's nature as the commercial hub of the country, with ever-increasing numbers of people looking to locate in the area, for both work and leisure, suggesting the necessity and availability of a much more developed market. But while 14 of the top 30 towns belong to this area, there is still a relatively good level of diversification amongst regions, with contenders from Wales to Yorkshire and Humberside and Scotland also gaining high positions in the ranking.

When the average scores for the region across all locations are examined, this trend of southern dominance in terms of investment potential holds true. The majority of sub-regions that achieve aboveaverage scores are from the south, with the West End clearly expected to have the potential to achieve returns in advance of any other region over the next ten years, averaging a score of 59.4 per cent, compared to the GB average of 50.0 per cent.

When the traditional areas of London, the West End and the City, are compared, there is a clear disparity between the two. The West End, which is possibly the most popular retail location in the country, is clearly expected to outperform the City, the capital's office heartland, by a significant margin in terms of retail potential over the medium term. Clearly, however, local issues of sub-market supply and current market pricing will determine to what extent actual performance matches potential.

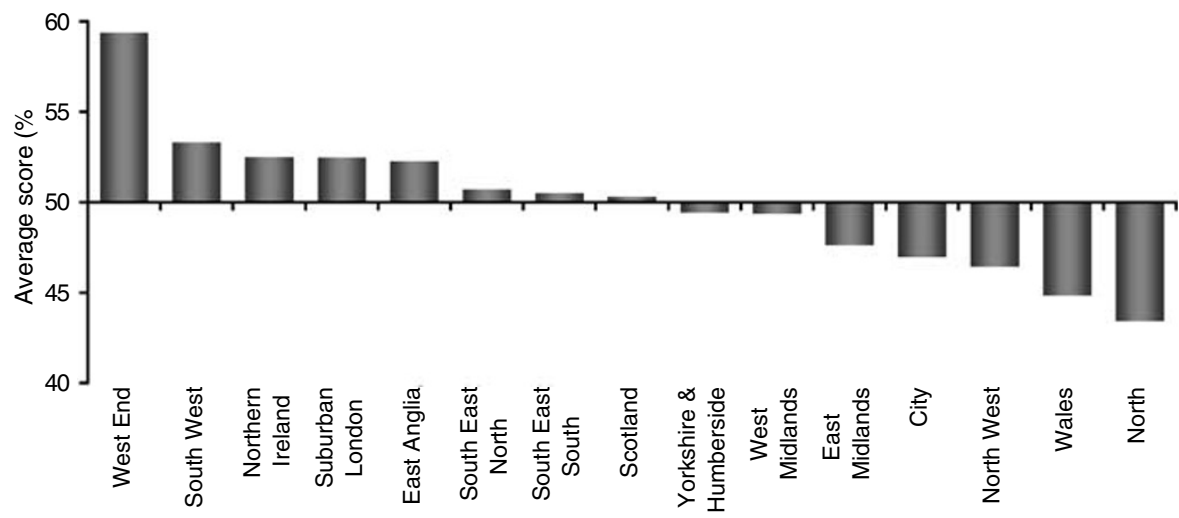

Figure 8: Average score by region (Great Britain $=50$ per cent) Source: Cushman \& Wakefield European Research Group 
The north-south divide that exists in the top 30 locations is maintained throughout the list. This is explained by both weaker property fundamentals and a relatively lacklustre labour market that continues to suffer from a skills mismatch.

\section{THE IMPACT OF CENTRE FORMAT}

A clear trend also results when the top 30 locations are examined by type of centre. Those locations which are deemed to show the most investment potential are largely defined as 'primary centres', a definition which encompasses the largest retail centres such as major cities that have a significant impact at a national and regional level. In fact, 15 of the top 30 belong to this grouping, suggesting that this format is becoming preferred, by both retailers and investors alike, over smaller, mid-marketfocused shopping formats. The remaining 15 locations also belong to the larger-style groupings, such as major centres (large towns or 'secondary' regional cities that possess sizeable retail markets), and this trend is reflected throughout the complete list in general.

When the total list of locations is examined in terms of the type of format of the retail market, there is a clear movement away from the small, localised, town-centre format for comparison stopping, with the more dominant sub-regional cities instead likely to outperform. Out-oftown regional malls are expected to see the most potential in the long term, as shown in Figure 9, albeit, of course, that this is already reflected in their investment pricing. This is a largely anticipated result given the increasing importance of regional malls, such as Bluewater and Lakeside, as preferred shopping destinations. These regional malls have a tendency to score well owing to strong underlying property fundamentals, such as accessibility and quality of stock, as well as their notably higher catchment populations and number of shoppers in general. Furthermore, planning restrictions placed on some major town centres ultimately enhance the attractiveness of the existing out-of-town destinations.

Those towns without identity or those that are less independently economically viable, for example as a tourist destination, will tend to lag in terms of investment potential. While some of these other rural and

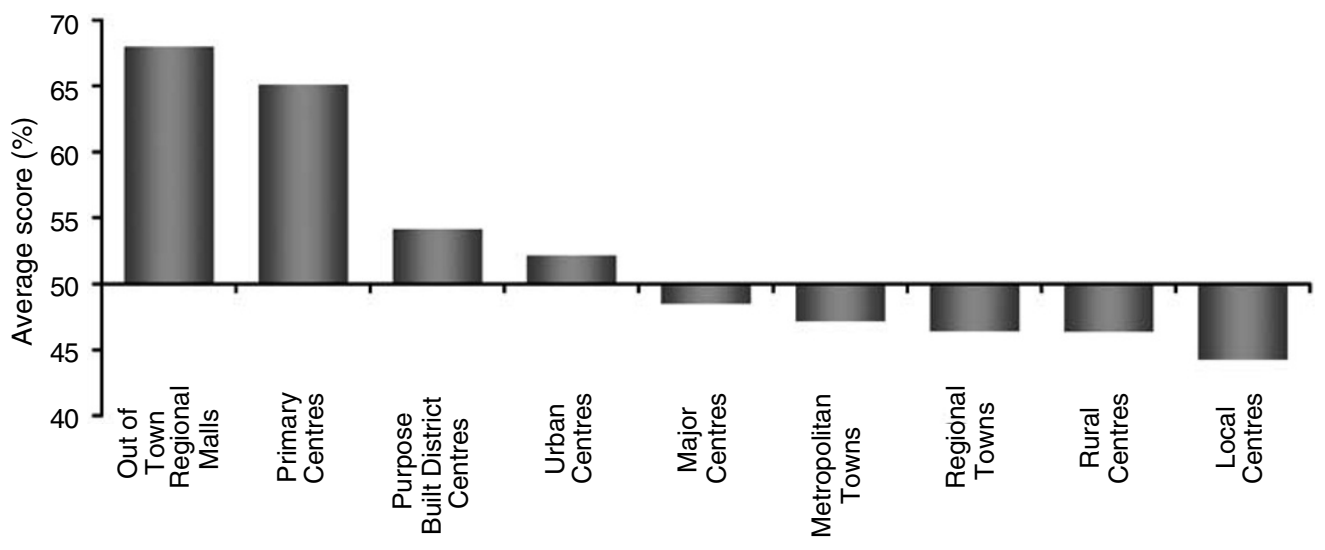

Figure 9: Average score by centre type (All centres $=50$ per cent) Source: $C A C l$, Cushman \& Wakefield European Research Group 
typically smaller local centres have a propensity to record healthy economic activity combined with a reasonable demographic profile over the next ten years, they are hindered by both limited structural potential within the property market and the relatively poor shopping environment.

Instead, the much larger, centralised primary centres will continue to expect to record higher growth and demand. The ability of larger centres to attract a significantly greater catchment population, for example, will continue to enable such centres to excel.

It is clear that, when considered by centre type, the economic outlook, while important, is of less importance than other features. Instead, a combination of strong property fundamentals, a healthy demographic profile and a positive environment tends to give the best profile in terms of long-run investment potential.

\section{ONE YEAR ON - THE MODEL REVISITED}

An update to the model was completed in autumn 2005, giving an ideal opportunity to see how locations in the list had changed over time, alongside changing perceptions of the market. Figure 10 shows the new ordering for the top 30 .

By and large, the top locations have remained the same, with only five new entrants to the list, all of which are in the second part of the list. Reading has remained top, with its underlying fundamentals still in advance of all other towns. Indeed the property-related variables in the

\begin{tabular}{|c|c|c|}
\hline Rank & Location & Region \\
\hline 1 & Reading & South East South \\
\hline 2 & Guildford & South East South \\
\hline 3 & Cambridge & East Anglia \\
\hline 4 & Newcastle-upon-Tyne & North \\
\hline 5 & Kingston-upon-Thames & Suburban London \\
\hline 6 & Manchester & North West \\
\hline 7 & Brighton & South East South \\
\hline 8 & Nottingham & East Midlands \\
\hline 9 & Glasgow & Scotland \\
\hline 10 & Oxford Street W1 & London West End \\
\hline 11 & Leeds & Yorkshire \& Humberside \\
\hline 12 & Cardiff & Wales \\
\hline 13 & Milton Keynes & South East North \\
\hline 14 & Leicester & East Midlands \\
\hline 15 & Birmingham & West Midlands \\
\hline 16 & Covent Garden WC2 & London West End \\
\hline 17 & Southampton & South East South \\
\hline 18 & Chester & North West \\
\hline 19 & Belfast & Northern Ireland \\
\hline 20 & Brompton Road SW3 & London West End \\
\hline 21 & Richmond & Suburban London \\
\hline 22 & Kings Road SW3 & London West End \\
\hline 23 & York & Yorkshire \& Humberside \\
\hline 24 & Canterbury & South East South \\
\hline 25 & Tunbridge Wells & South East South \\
\hline 26 & Chelmsford & South East North \\
\hline 27 & Croydon & Suburban London \\
\hline 28 & Oxford & South East North \\
\hline 29 & Marylebone High Street & London West End \\
\hline 30 & Bath & South West \\
\hline
\end{tabular}


town have shown a relative improvement over the year compared to the other locations in the list.

There has, however, been notable movement within this top grouping itself due to the movements of locations such as Oxford Street, which has been surpassed by other locations in terms of its relative standing in the views of the retail and investment markets. This has, to some extent, been due to the terrorist bombings of July 2005 and the impact of these on tourism in particular; but other issues, such as congestion charging and the Street's competitive offer versus newer schemes and other London thoroughfares, are also acting to affect the attractiveness of the location.

The most improved town now in the top 30 is Tunbridge Wells, which has risen from last year's position of 60 to reach number 25 . While there has been some improvement in terms of the perceptions of the local property market, much of this progress has been the result of more positive expectations for the economy. Ten-year GDP and employment growth forecasts in particular, saved from experian, have been upgraded significantly, which has had the knock-on effect of improving local consumer spending expectations. Consequently, the retail outlook for the town has become much more optimistic.

Outside of the top 30, there has also been significant change within the list as a whole. The most notable shift, although somewhat expected, has been the movement of Stratford in London from number 243 to a muchimproved 114. This, of course, is predominantly due to the awarding of the 2012 Olympics to London, which is expected to accelerate the redevelopment of the East London area in general, and Stratford, the planned location for the Olympic Park, in particular. As a result, expectations of improved transport links, increased employment and increased economic growth have lifted the perceptions of the town from all perspectives and, most notably, in terms of the local property market.

\section{CONCLUSION}

In summary, the model suggests that outperformance will be achieved by those towns which are known to be major retail locations, having a solid demographic base, healthy economies and already-strong property fundamentals, both from a retail and an investment perspective, including Reading, Kingston-upon-Thames and Guildford.

At a regional level, locations with the most potential tended to be located in the south of the country and, in particular, in London. Northern regions were expected to lag, especially in terms of economic and property-related factors.

At centre-type level, there was also an obvious trend of a movement away from smaller, more localised locations to regional urban centres. The most potential over the next ten years will result from the regional mall format, a logical prospect given their recent expansion and robust rental growth rates.

According to the model, therefore, those locations which are likely to boast the greatest returns over the next ten years or so tend to be focused on specific areas and centre types, with the south in general, and London in particular, continuing to present greater investment opportunities on a 
regional basis, while larger regional centres, including out-of-town shopping malls, will yield healthier returns by centre type.

The model also, however, helps to demonstrate what factors smaller centres must address if they are to win a healthier position in the retail hierarchy and highlights some markets with clear potential to do this. Indeed, when compared with an analysis of current market pricing, it is often mid-sized centres rather than well-supported local markets which are at most risk of future underperformance.

The model raises some interesting results, but the conclusions that can be drawn should not be restrictive. This forms a starting point in identifying new targets in the UK retail market, but the importance of careful stock selection remains paramount in making the best investment decision, especially in the current buoyant property market. Good value is increasingly difficult to find, and with the emphasis now turning to longer-term investment gains, as short-term uncertainties are on the up, models such as $\mathrm{C} \& \mathrm{~W}$ TopTowns enable longer term fundamentals that drive investment performance to be identified and serve as a tool to assist in making careful investment decisions. 